\section{Preliminary results of spatial distribution of uranium and thorium in soil profiles near a uranium industrial site, Guangdong province, China}

\begin{abstract}
Four soil profiles were collected from locations with different distances (5, 50, 250 and 1000 $\mathrm{m}$ ) from a uranium mill tailings dam, Guangdong province, China, to investigate the pollution status of the soil in mining/ milling-related areas based on the contents of uranium (U) and thorium (Th), thus to understand the impacts of uranium industrial activities to the surroundings. The $\mathrm{U}$ and $\mathrm{Th}$ concentrations were determined by inductively coupled plasma mass spectrometry (ICP-MS) after conventional $\mathrm{HF}-\mathrm{HNO}_{3}-\mathrm{HClO}_{4}$ digestion procedures. The results indicate that the soils within $50 \mathrm{~m}$ from uranium tailing were severely contaminated; those in 250 and $1000 \mathrm{~m}$ soil samples were observed to be with local background level even though these in $250 \mathrm{~m}$ had slightly higher U/Th ratios. Uranium concentrations varied from $5.50 \pm 0.27$ to $160.55 \pm 8.03 \mathrm{mg} / \mathrm{kg}$, with maximum values recorded in an intermediate layer of the 5-m distance soil profile. In comparison, the concentration of Th ranged from $6.02 \pm 0.30$ to $84.71 \pm 4.24 \mathrm{mg} / \mathrm{kg}$, with maximum values observed in the top layer of the 1000-m distance soil profile. The U/Th ratio varied from 0.15 to 11.99 compared with $0.20,0.22$ and 0.26 of the average for Guangdong province, national China and the world, respectively. The mean U/Th of four soil profiles showed a reduction with distance from the uranium mill tailing dam, suggesting the relatively large magnitude of uranium elevation in soils within limited distances.
\end{abstract}

Key words: spatial distribution $\bullet$ thorium $\bullet$ uranium $\bullet$ U/Th ratio

J. Wang, G. Song, D. Y. Chen, F. Jiang

School of Environmental Science and Engineering,

Guangzhou University

and Guangdong Provincial Key Laboratory

of Radionuclides Pollution Control and Resources,

230 Waihuan West Str., 510006 Guangzhou, China

\section{J. Liu, Y. H. Chen ${ }^{\bowtie}$, H. S. Li}

Innovation Center and Key Laboratory of Waters Safety \& Protection in the Pearl River Delta,

Ministry of Education,

Guangzhou University,

230 Waihuan West Str., 510006 Guangzhou, China,

Tel.: +86 203936 6937, Fax: +86 203936 6946,

E-mail: chenyong_heng@163.com

\section{T. F. Xiao}

State Key Laboratory of Environmental Geochemistry, Institute of Geochemistry, Chinese Academy of Sciences, 99 Lincheng West Str., 550081 Guiyang, China

\section{L. Wang}

Guangdong Provincial Academy of Environmental

Science,

335 Middle Dongfeng Str., 510045 Guangzhou, China

Received: 5 December 2015

Accepted: 1 April 2016

\section{Introduction}

The environmental issues concerning uranium mining and milling have long been paid considerable attention in wide aspects in the world [1-4]. It is well known that the industrial activities of mining and milling of uranium ores can lead to release of a tremendous amount of radioactive pollutants (wastewater and tailings, as representative carrier) that consist typically of $U$ and Th compounds. Also, the unintended stacking of uranium ores and waste rocks in surface environment would result in leaching of $U$ and Th under weathering and meteorological conditions. Once being improperly treated, these radioactive pollutants can directly transfer to the environmental media, posing a significant threat to the ecosystem and public health in the light of their radioactivity, toxicity, accumulation in the food chain and long-term persistence in nature [5-7].

In the context of increased demand for uranium resulting from skyrocketing development of nuclear power plants in China, it is encouraged to carry out investigation on uranium-induced pollution and remediation strategy. In the present study, a large granitic-type uranium deposit in Guangdong, China, was selected, whose mining and milling activities commenced from 1960s. After 50 years of operation, 
the distribution and level of radioactive elements in surrounding soil environment is of great concern. It is natural to wonder whether the local soil is safe for agriculture use. Therefore, the main aim of this work is to investigate the pollution status and influencing scale of this uranium industrial site and the related mining/milling activities to the ambient soil environment with the focus on $\mathrm{U}$ and Th. Herein, four soil profiles with different distances from mill tailings dam were studied to preliminarily illustrate the spatial distribution of $U$ and $T h$ in the studied area and give insight into the fate and evolution of these two elements in the soil medium under the circumstance of anthropogenic influence of uranium mining/milling-related activities.

\section{Experimental}

\section{Sample collection}

As schematically shown in Fig. 1, four soil profiles were selected and sampled in the vicinity of a uranium mill tailings area and downstream area during a pilot survey in December 2011. With the purpose of investigating the pollution status and influencing scale, the selection criteria of sampling points is based on mixed wind direction and water flow direction; more sampling points were selected close to the most polluted site and less ones far away from pollution source. To prevent the sampling contamination, the four soil profiles were collected beginning from the most remote to the industrial sites, marked as A, B, C and D, which were with different linear distances of about 1000, 250, 50 and $5 \mathrm{~m}$, respectively, away from the uranium mill tailings dam. The total collection of 75 samples were from different depths of $1,2,3,4,5,10,15,20,25$, $30,35,40,45,50,55,65,75,85$ and $100 \mathrm{~cm}$ for each soil profile. Each individual soil sample was carefully excavated, mixed homogeneously and immediately placed in plastic bags.

\section{Sample preparation and analytical methods}

Before laboratory analysis, all glassware and Teflon beakers were soaked in a $0.2 \mathrm{~mol} / \mathrm{L}_{\mathrm{HNO}}$ solution for $24 \mathrm{~h}$ and then rinsed with ultra-pure water $(18.25 \mathrm{M} \Omega / \mathrm{cm})$ from a MilliQ-system (Millipore, Milford Corp., USA). Soil samples were air dried at $25^{\circ} \mathrm{C}$ and were ground to pass through a $0.149-\mathrm{mm}$ nylon sieve. Hundred milligram of each soil sample

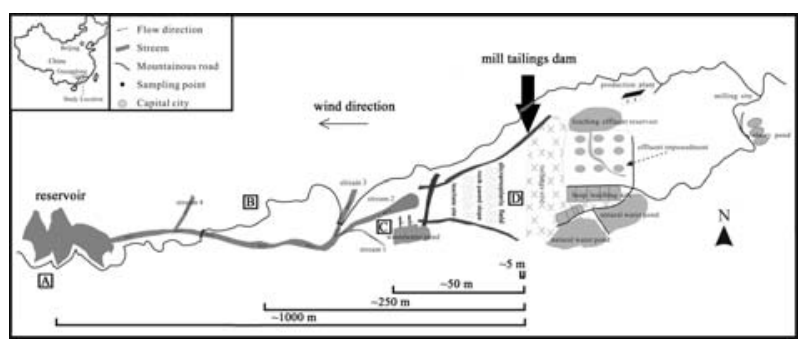

Fig. 1. Schematic display of soil profiles location. was accurately weighed and carefully transferred in a 50-mL Teflon beaker, then followed with $\mathrm{HF}-\mathrm{HNO}_{3}-$ $-\mathrm{HClO}_{4}$ digestion method on an electrothermal plate. Nitric acid $\left(\mathrm{HNO}_{3}\right)$, hydrofluoric acid (HF), and perchloric acid $\left(\mathrm{HClO}_{4}\right)$ were all of super-pure grade.

The measurements of $U$ and $T h$ were performed with inductively coupled plasma mass spectrometry (ICP-MS, PerkinElmer, Elan 6000) at the Guangzhou Institute of Geochemistry, Chinese Academy of Sciences. A certified reference material was digested along with the samples to assure the precision and accuracy of analysis. The coefficients of variation of triplicate analysis for the studied elements were below $10 \%$, and the accuracy was confirmed to be within $\pm 5 \%$.

For the determination of soil $\mathrm{pH}$, the method described in Ref. [8] was adopted. Air dried soil samples were mixed with ultra-pure water with a ratio of $1: 2.5$ (soil:water) and the $\mathrm{pH}$ of the clear supernatant was measured using a $\mathrm{pH}$ meter (Sartorius $\mathrm{pH}-2 \mathrm{C}$, Germany).

\section{Results and discussion}

It is visible from Fig. 2 that the concentration of $U$ in profile A is very low, which seems to be affected by little anthropogenic factors. However, $\mathrm{U}$ and $\mathrm{Th}$ contents in the profile are not seemingly low, that is, $5.50 \pm 0.27$ to $19.37 \pm 0.97 \mathrm{mg} / \mathrm{kg}$, averaged $11.83 \pm 0.59 \mathrm{mg} / \mathrm{kg}$, and $17.57 \pm 0.88$ to $84.71 \pm$ $4.24 \mathrm{mg} / \mathrm{kg}$, averaged $58.09 \pm 2.90 \mathrm{mg} / \mathrm{kg}$, respectively, both twice the values of Guangdong province (the average $U$ and $T h$ concentrations of 5.51 and $27.92 \mathrm{mg} / \mathrm{kg}$, respectively) [9] and greatly exceeding the soil background value of $2.79 \mathrm{mg} / \mathrm{kg}$ in national China and the world of $2.0 \mathrm{mg} / \mathrm{kg}$ for $U[10,11]$. Furthermore, both the maximum values emerged at the surface layers.

Many researchers use concentration ratios of $\mathrm{U} / \mathrm{Th}$ to illustrate the U-related enrichment or contamination $[12,13]$. In particular, the U/Th ratio may distinguish $U$ resulting from the artificial sources such as manufacture of nuclear fuels, coal-combustion or from natural sources and indicate the relative level of $U$ elevation [12]. In the present study, as shown in Fig. 3, the ratios in profile A ranged from 0.15 to 0.31 , averaged 0.21 , which is

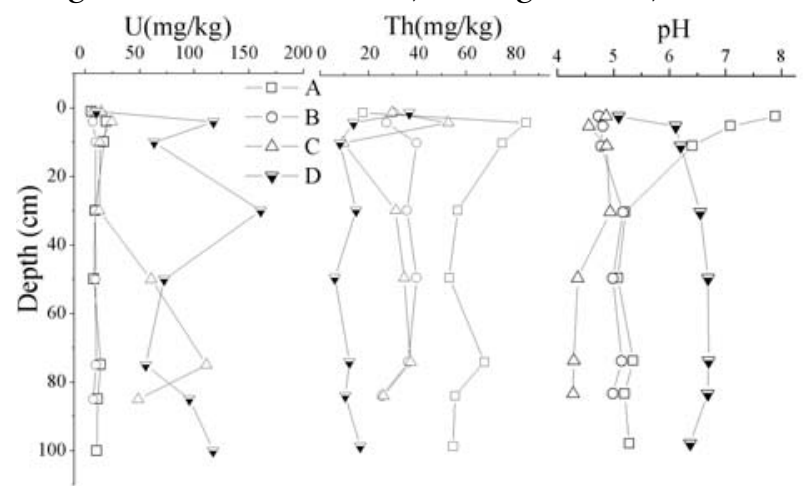

Fig. 2. Spatial distribution of $U$ and Th in profiles of A, B, $\mathrm{C}$ and $\mathrm{D}$. The measurement uncertainty of concentrations for the two elements is about $5 \%$. 


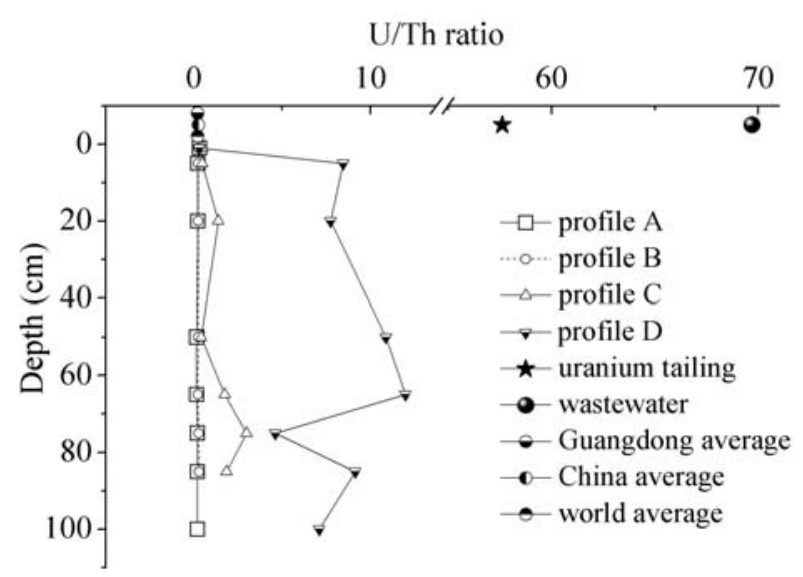

Fig. 3. The comparison of concentration ratios of U/Th between four soil profiles studied and the average values referenced.

slightly higher than the average of Guangdong province $(0.20)$ but in near agreement with the average of national China $(0.22$, based on the average $U$ and Th concentrations of 2.79 and $12.8 \mathrm{mg} / \mathrm{kg}$, respectively), non-agricultural fields in Japan (0.23) [13], 0.19-0.31 for surface soil around potential uranium mining site in India [14], and reported world average of 0.26 [15]. These data imply that the contents of $\mathrm{U}$ and Th are natural-occurring background, in spite of being both with higher concentrations.

Therefore, the variations of concentrations of $U$ and Th across the profile may relate to the process of natural weathering, evolution and mineral bound leaching. The upper layer of soils with dramatically high $\mathrm{pH}$ might be linked to composed alkaline mineral or occasionally residual lime by human to prevent the trees from the worms and pests.

As shown in Fig. 2, the $U$ and Th contents in the profile $\mathrm{B}$ are much lower when compared to profile A, that is, $6.93 \pm 0.35$ to $9.7 \pm 0.49 \mathrm{mg} / \mathrm{kg}$, averaged $8.44 \pm 0.42 \mathrm{mg} / \mathrm{kg}$, and $27.31 \pm 1.37$ to $39.66 \pm$ $1.98 \mathrm{mg} / \mathrm{kg}$, averaged $33.47 \pm 1.67 \mathrm{mg} / \mathrm{kg}$, respectively, but higher than the value of Guangdong province [9], national China and the world average for $U$ [10, 11]. Concentration ratios of $\mathrm{U} / \mathrm{Th}$ were in a range from 0.23 to 0.29 , averaged 0.25 , subtly higher than profile $\mathrm{A}$, but it is still comparable with the values from Guangdong, national China and the world (Fig. 3). Nonetheless, the lower $\mathrm{pH}$ values of upper soils might be associated with sulfuric acid leaching activities. It is worthy to note that heap leaching site was about $500 \mathrm{~m}$ away, where huge amount of sulfuric acid was used to leach uranium ores. The aerosol particles combined with droplets of sulfuric acid, under the suitable meteorological circumstances, might transport with long distance. As the profile B was in a lower and smooth terrain compared with heap leaching sites, thus it was susceptible to the airborne acid transport. Therefore, even though the concentrations of $U$ and Th comprehensively represented natural levels, it was probably subtly affected by the uranium industrial activities to some degree.

As to profile $\mathrm{C}$, as shown in Fig. 2, the U concentrations were rather high in deeper samples while Th represented normal contents compared to profile A and $\mathrm{B}$. It indicates the process in which a great deal of $U$ has largely migrated vertically down the profile, other than Th, as a result of quite different chemical properties. The special geographical location of this soil profile may help understand the high occurrence of U. Around profile C, there was a polluted stream (stream 2 in Fig. 1), where were located with the outlets of processed wastewater piped from milling area, also a wastewater pond full of pipelined effluent ( $\mathrm{pH} \sim 3-4)$ with $2.091 \mathrm{mg} / \mathrm{L}$ of $U$ and $0.030 \mathrm{mg} / \mathrm{L}$ of Th in the close vicinity found in our earlier investigation [6]. Furthermore, the tailing seepage (even though the flow was fairly small) with $1.863 \mathrm{mg} / \mathrm{L} \mathrm{U}$ also directly discharged into the stream. On the one hand, the fact that the very low $\mathrm{pH}$ values of soils ranged from 4.28 to 4.94 demonstrated the homology of acidity between soil and discharged wastewater. Therefore, it may be deduced that the U migrated into the soil profile by means of aqueous transfer from the polluted stream. On the other hand, the influence from heap leaching activities only about $300 \mathrm{~m}$ away together with meteorological condition might not be neglected. It could further acidify the soil and expedite the migration of $U$ into the solid phase.

The U concentrations in 1-30 cm depth of soil layers almost keep constant, then show a sharp increase downwards and reach an extremum at the depth of $75 \mathrm{~cm}$, where a layer of humus were distinctively observed. The drastic variation of $\mathrm{pH}$ amongst the depth of $30-45 \mathrm{~cm}$ in the soil profile might provide the evidence for the existence of acid substances such as humic acid (HA), as representative of humus, which has been proved to effectively absorb U, and strong complexation between $\mathrm{HA}$ and $\mathrm{U}(\mathrm{VI})$ under a wide range of environmental conditions has been extensively studied [16-18].

In terms of concentration ratios of $\mathrm{U} / \mathrm{Th}$ in this soil profile, as exhibited in Fig. 3, they were in a range from 0.41 to 2.98 , averaged 1.33 , which is significantly larger than those in profile $\mathrm{A}, \mathrm{B}$, and the average of Guangdong province, national China, and the world as well. The wastewater with a U/Th ratio of 69.7 was highly expected to contribute the source to profile $\mathrm{C}$ based on above-mentioned reasons.

For the profile D, as clearly seen from Fig. 2, disturbed distributions of $U$ and Th across the profile were observed. The reason why the top $5 \mathrm{~cm}$ of soil was with extremely low concentration of $U$ and significantly higher Th content across the whole profile might attribute to the great mass of vegetation in the topsoil, which would have favourably assimilated U while facilitated immobilization of Th in the biological process. The variation of $\mathrm{pH}$ in the soil profile also illustrate the biological effect in the upper layer. Alternative reason could also ascribe to the physicochemically active property of $U$ and relatively inert for Th. As Th tends to be tightly adsorbed by the soil particles, not easy to be leached out, its capability of horizontal or vertical migration would be much weaker in contrast to $U$. Except for the top layer of soil, the deeper soil profile display somehow similar trend for $\mathrm{U}$ and $\mathrm{Th}$, in despite of much more dispersed distribution of the 
former element. The maximum value of $U$ appeared in the intermediate layer of the profile, indicating relatively long history of vertical migration from the surface. The fluctuations of the concentrations suggest different periods of pollution from uranium tailing surrounded in the terms of concentration ratios of $\mathrm{U} / \mathrm{Th}$. The values are in a range from 0.28 to 11.99 , averaged 7.53 , which is the largest amongst the four soil profiles, as shown in Fig. 3, indicating the relatively large magnitude of uranium elevation. The local uranium tailing with $\mathrm{U} / \mathrm{Th}$ ratio of 57.62 was likely to contribute the source to profile $\mathrm{D}$ mainly owing to the geographic location.

\section{Conclusions}

Measurements of $\mathrm{U}$ and Th concentrations as well as concentration ratios of $\mathrm{U} / \mathrm{Th}$ in four soil profiles near a uranium mining/milling site, Guangdong province, China, have provided valuable information on horizontal and vertical distribution of $\mathrm{U}$ and $\mathrm{Th}$ contamination in soils in typical Chinese uranium industrial activities, indicating and distinguishing both the magnitude and source of the two elements from uranium industrial operations and natural background. Owing to the discriminative properties between $\mathrm{U}$ and $\mathrm{Th}$, the latter is susceptible to tight adsorption by the soil particles, relatively difficult to be leached out; its capability of horizontal or vertical migration would be much weaker compared to U. Accordingly, maximum $U$ concentration was detected in an intermediate layer of the 5-m distance soil profile, while maximum Th content was observed in the top layer of the 1000-m distance soil profile.

To sum up, the horizontal influence with respect to $\mathrm{U}$ and $\mathrm{Th}$ concentrations in soil environment by the local uranium industrial activities was temporally limited within $50 \mathrm{~m}$ in distance. The samples in 250and $1000-\mathrm{m}$ soil profiles primarily exhibited natural level, rather than the anthropological influence. However, in the soil profile in $1000 \mathrm{~m}$ in spite of very low U/Th, its background level of Th concentration was with high elevation and, therefore, it is not suitable for agricultural use. Even though preliminary results have been obtained, more comprehensive and larger-scale investigations are needed to understand the profound geochemical process involving $\mathrm{U}$ and Th migration in soils under stress from increasingly enhanced anthropological activities.

Acknowledgment. The work was supported by the National Natural Science Foundation of China (41303007, 41372364, 41373117, 41573008, U1501231, 41573119 and 41273100), Guangdong Provincial Natural Science Foundation (2015A030313512 and 2014A030313527) and Guangzhou Education Bureau (1201431072). We would like to thank anonymous reviewers who significantly improved the quality of the paper.

The work was performed in 510006 Guangzhou, Guangdong province, China.

\section{References}

1. Landa, E. R., \& Gray, J. R. (1995). US Geological Survey research on the environmental fate of uranium mining and milling wastes. Environ. Geol., 26, 19-31. DOI: 10.1007/BF00776028.

2. Lovley, D. R., \& Phillips, E. J. P. (1992). Bioremediation of uranium contamination with enzymatic uranium reduction. Environ. Sci. Technol., 26, 2228-2234. DOI: 10.1021/es00035a023.

3. Mkandawire, M., \& Dudel, E. G. (2005). Accumulation of arsenic in Lemna gibba L. (duckweed) in tailing waters of two abandoned uranium mining sites in Saxony, Germany. Sci. Total Environ., 336, 81-89. DOI: 10.1016/j.scitotenv.2004.06.002.

4. Tykva, R., \& Podracká, E. (2005). Bioaccumulation of ${ }^{226} \mathrm{Ra}$ in the plants growing near uranium facilities. Nukleonika, 50(Suppl. 1), S25-S27.

5. Liu, J., Wang, J., Li, H. C., Shen, C. C., Chen, Y. H., Wang, C. L., Ye, H. Z., Long, J. Y., Song, G., \& Wu, Y. J. (2015). Surface sediment contamination by uranium mining/milling activities in South China. Clean-Soil Air Water, 43, 414-420. DOI: 10.1002/clen.201300297.

6. Wang, J., Liu, J., Li, H. C., Song, G., Chen, Y. H., Xiao, T. F., Qi, J. Y., \& Zhu, L. (2012). Surface water contamination by uranium mining/milling activities in Northern Guangdong Province, China. Clean-Soil Air Water, 40, 1357-1363. DOI: 10.1002/ clen.201100512.

7. Wang, J., Liu, J., Zhu, L., Qi, J. Y., Chen, Y. H., Xiao, T. F., Fu, S. M., Wang, C. L., \& Li, J. W. (2012). Uranium and thorium leached from uranium mill tailing of Guangdong province, China and its implication for radiological risk. Radiat. Prot. Dosim., 152, 215-219. DOI: $10.1093 / \mathrm{rpd} / \mathrm{ncs} 229$.

8. Shi, W. M., Yao, J., \& Yan, F. (2009). Vegetable cultivation under greenhouse conditions leads to rapid accumulation of nutrients, acidification and salinity of soils and groundwater contamination in South-Eastern China. Nutr. Cycl. Agroecosys., 83, 73-84. DOI: 10.1007/s10705-008-9201-3.

9. Environmental Monitoring Station of China. (1990). Background values of soil elements in China. Beijing: China Environmental Science Press (in Chinese).

10. Bowen, H. J. M. (1979). Environmental chemistry of the elements. London: Academic Press.

11. Xie, H. Y., Hu, J. S., Yin, J., \& Ding, D. X. (2014). Plant composition in certain uranium tailings area in China and their accumulation on uranium. Atom. Energy Sci. Technol., 48, 1954-1959 (in Chinese).

12. Bellis, D. J., Ma, R., \& Mcleod, C. W. (2001). Characterisation of airborne uranium and thorium contamination in northern England through measurement of $\mathrm{U}$, Th and ${ }^{235} \mathrm{U} /{ }^{238} \mathrm{U}$ in tree bark. J. Environ. Monit., 3, 198-201. DOI: 10.1039/B009220G.

13. Tagami, K., \& Uchida, S. (2006). Use of a natural $\mathrm{U} / \mathrm{Th}$ concentration ratio for estimation of anthropogenic uranium concentration in Japanese agricultural soils due to application of phosphatic fertilizers. $R a$ dioisotopes, 55, 71-78.

14. Sartandel, S. J., Jha, S. K., Bara, S. V., Tripathi, R. M., \& Puranik, V. D. (2009). Spatial distribution of uranium and thorium in the surface soil around proposed uranium mining site at Lambapur and its vertical profile in the Nagarjuna Sagar Dam. $J$. Environ. Radioact., 100, 831-834. DOI: 10.1016/j. jenvrad.2009.06.005.

15. Chandrasekaran, A., Ravisankar, R., Senthilkumar, G., Thillaivelavan, K., Dhinakaran, B., Vijayagopal, P., Bramha, S. N., \& Venkatraman, B. (2014). Spatial 
distribution and lifetime cancer risk due to gamma radioactivity in Yelagiri Hills, Tamilnadu, India. Egypt. J. Basic. Appl. Sci., 1, 38-48. DOI: 10.1016/j. ejbas.2014.02.001.

16. Gao, Y., Shao, Z., \& Xiao, Z. (2015). U(VI) sorption on illite: effect of $\mathrm{pH}$, ionic strength, humic acid and temperature. J. Radioanal. Nucl. Chem., 303, 867-876. DOI: 10.1007/s10967-014-3385-6.

17. Ivanov, P., Griffiths, T., Bryan, N. D., Bozhikov, G., \& Dmitriev, S. (2012). The effect of humic acid on ura- nyl sorption onto bentonite at trace uranium levels. J. Environ. Monit., 14, 2968-2975. DOI: 10.1039/ C2EM30512G.

18. Joseph, C., Schmeide, K., Sachs, S., Brendler, V. Geipel, G., \& Bernhard, G. (2011). Sorption of uranium (VI) onto Opalinus Clay in the absence and presence of humic acid in Opalinus Clay pore water. Chem. Geol., 284, 240-250. DOI: 10.1016/j. chemgeo.2011.03.001. 